\title{
Protective action of Citrullus colocynthis seed extracts against the deleterious effect of streptozotocin on both in vitro glucose-stimulated insulin release from rat pancreatic islets and in vivo glucose homeostasis
}

\author{
NABILA BENARIBA $^{1,2}$, WAFAA BELLAKDHAR ${ }^{1}$, RABEH DJAZIRI $^{1}$, \\ EMELINE HUPKENS $^{2}$, KARIM LOUCHAMI ${ }^{2}$ and WILLY J. MALAISSE ${ }^{2}$ \\ ${ }^{1}$ Laboratory of Antibiotic and Antifungal Physico-Chemistry, Synthesis and Biological Activity, Faculty of Sciences, \\ University Abou Bekr Belakaïd, Tlemcen, Algeria; \\ ${ }^{2}$ Laboratory of Experimental Hormonology, Free University of Brussels, Brussels, Belgium
}

Received July 4, 2012; Accepted August 17, 2012

DOI: $10.3892 /$ br.2012.5

\begin{abstract}
Citrullus colocynthis extracts improve glucose homeostasis in alloxan- or streptozotocin (STZ)-induced diabetic rats. Little is known, however, regarding the protective effect of these extracts against the $\beta$-cytotoxic action of STZ. In the present study, an $\mathrm{H}_{2} \mathrm{O}$-methanol extract was found to suppress the inhibition of glucose-stimulated insulin secretion by STZ in rat-isolated pancreatic islets. Similarly, when an aqueous extract from Citrullus colocynthis seeds was injected daily for 21 days prior to STZ administration, the perturbation of glucose homeostasis otherwise generated by the $\beta$-cytotoxic agent was minimized in rats.
\end{abstract}

\section{Introduction}

Citrullus colocynthis extracts were reported to have beneficial effects on glucose homeostasis and body weight maintenance, in either alloxan- or streptozotocin (STZ)-induced diabetic rats $(1,2)$. The present study aimed to examine the possible protective action of Citrullus colocynthis extracts against the diabetogenic actions of STZ, since information currently available on the subject is insufficient. (1). To this end, the in vitro effect of an $\mathrm{H}_{2} \mathrm{O}$-methanol Citrullus colocynthis seeds extract on the deleterious effect of STZ in glucose-stimulated insulin secretion from isolated rat pancreatic islets was initially exam-

Correspondence to: Professor Willy J. Malaisse, Laboratory of Experimental Hormonology, Université Libre de Bruxelles, 808 Route de Lennik, B-1070 Brussels, Belgium

E-mail:malaisse@ulb.ac.be

Key words: Citrullus colocynthis extracts, streptozotocin, glucose-stimulated insulin release, rat isolated pancreatic islets, glycemia ined. Additionally, the protective action of an aqueous extract from Citrullus colocynthis seeds against the STZ-induced impairment of glucose homeostasis was investigated in vivo in rats.

\section{Materials and methods}

The aqueous extract of Citrullus colocynthis seeds was prepared as described in a previous study (3). For the hydromethanolic extract, $50 \mathrm{~g}$ of seeds were ground and defatted in hexane. This material was then heated and stirred 3 times for $3 \mathrm{~h}$ in a water:methanol mixture (30:70). Following filtration and centrifugation, the solution was evaporated until dry, and a hygroscopic red-orange residue (4.5\% dry matter) was obtained.

STZ was purchased from Sigma Chemical Co. (St. Louis, MO, USA).

The in vitro experiments were carried out in islet groups ( $n=8 /$ group), obtained from fed female Wistar rats. Islets were prepared by the collagenase procedure (4) and incubated for two successive periods of $60 \mathrm{~min}$ each at $37^{\circ} \mathrm{C}$ in $1.0 \mathrm{ml}$ of a salt-balanced medium (5) containing $1.0 \mathrm{mg} / \mathrm{ml}$ bovine serum albumin, $16.7 \mathrm{mM}$ D-glucose and, as required, STZ $(1.9 \mathrm{mM})$ and/or the $\mathrm{H}_{2} \mathrm{O}$-methanol extract $(500 \mu \mathrm{g} / \mathrm{ml})$. The insulin content of the incubation media was measured using radioimmunoassay (6).

The in vivo experiments were carried out using female Wistar rats injected intraperitoneally with saline $(5 \mathrm{ml} / \mathrm{kg}$ body wt.) or with crude aqueous extract ( $90 \mathrm{mg} / \mathrm{kg}$ body wt.), either daily for 21 successive days, or only once $24 \mathrm{~h}$ prior to the intraperitoneal injection of STZ $(0.25 \mathrm{mmol} / \mathrm{kg}$ body wt.). The glycemia was measured in blood samples collected from the tail tip, using a glucometer (Accu-Chek).

The results are presented as the mean values $( \pm$ SEM) with the number of individual determinations (n) or the degree of freedom (df). The statistical significance of differences between the mean values was assessed using the Student's t-test. 

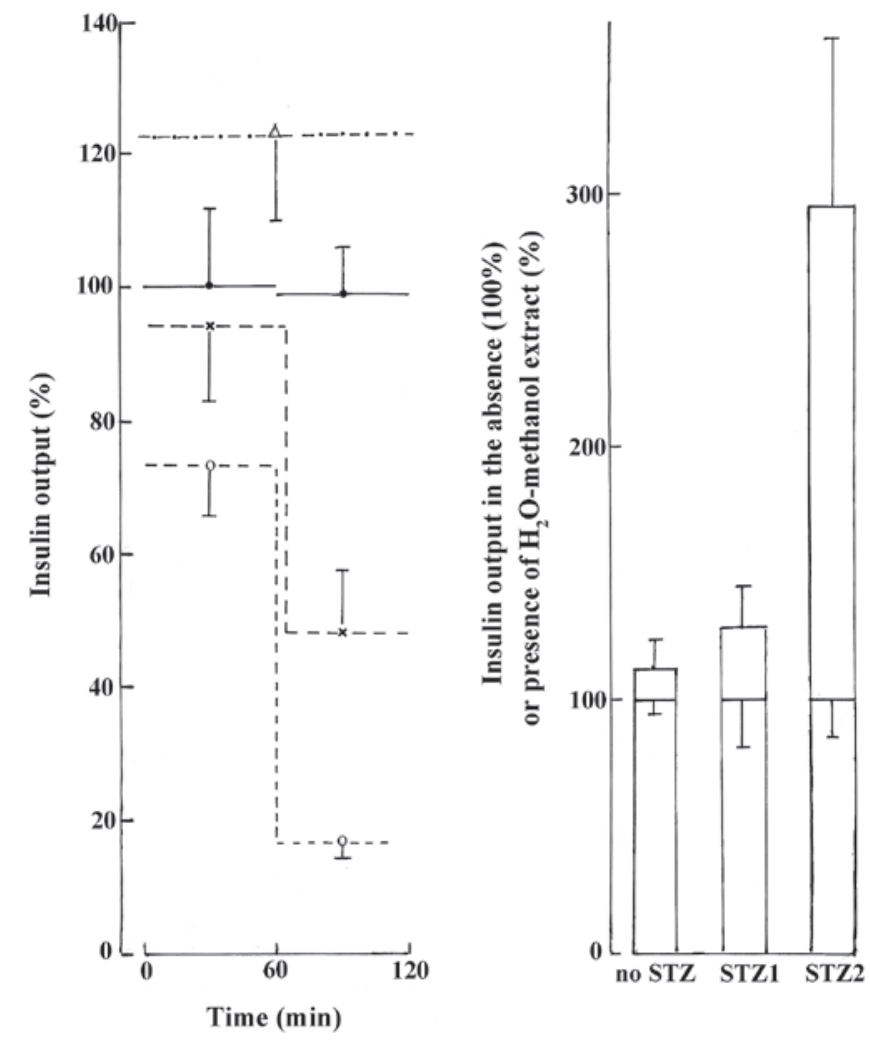

Figure 1. Left panel: insulin output over two successive 60-min incubations conducted in the sole presence of D-glucose $(16.7 \mathrm{mM}$; closed circles and solid line) or in the presence of the hexose and the $\mathrm{H}_{2} \mathrm{O}$-methanol extract (500 $\mu \mathrm{g} / \mathrm{ml}$; open triangle and dash-dotted line), streptozotocin (STZ) (1.9 mM; open circles and dotted line), or both the $\mathrm{H}_{2} \mathrm{O}$-methanol extract and STZ (crosses and dashed line). The mean values ( \pm SEM) for insulin output are expressed as a percentage of the average insulin output recorded within the same experiment(s) during the first incubation in the sole presence of D-glucose and refer to 17-20 (open and closed circles, crosses) or 39 (open triangle) individual determinations. Right panel: effect of the $\mathrm{H}_{2} \mathrm{O}$-methanol extract upon insulin output from islets incubated in the absence (no STZ) or the presence of STZ during the first incubation (STZ-1) or both the first and second incubation (STZ-2). The mean values ( \pm SEM) are expressed relative to the average insulin output recorded during the same experiment(s) and incubation period in islets exposed to D-glucose in the absence of the $\mathrm{H}_{2} \mathrm{O}$-methanol extract and refer to 37-39 (no STZ) or 18-19 (STZ-1 and STZ-2) individual determinations.

\section{Results}

In vitro experiments. The aim of the first series of experiments was to investigate whether the $\mathrm{H}_{2} \mathrm{O}$-methanol extract $(500 \mu \mathrm{g} / \mathrm{ml})$ had a protective effect against the deleterious effect of STZ $(1.9 \mathrm{mM})$ on the insulinotropic action of D-glucose $(16.7 \mathrm{mM})$. To this end, the islets were incubated for two successive periods of $60 \mathrm{~min}$ each, either solely in the presence of D-glucose or with this hexose, STZ and/or the $\mathrm{H}_{2} \mathrm{O}$-methanol extract. Over the two successive 60-min incubations with only D-glucose, the average insulin output during the second incubation remained relatively stable $(99.1 \pm 6.7 \%$, $\mathrm{n}=20)$, compared to the first incubation $(100.0 \pm 11.9 \%, \mathrm{n}=17)$. In the presence of the $\mathrm{H}_{2} \mathrm{O}$-methanol extract the average insulin output during the first and second incubation periods was $112.4 \pm 11.0 \%(n=39 ; P>0.34)$, compared to the mean corresponding values found within the same experiment(s) in the sole presence of D-glucose $(100.0 \pm 6.2 \%$; $n=37)$ during

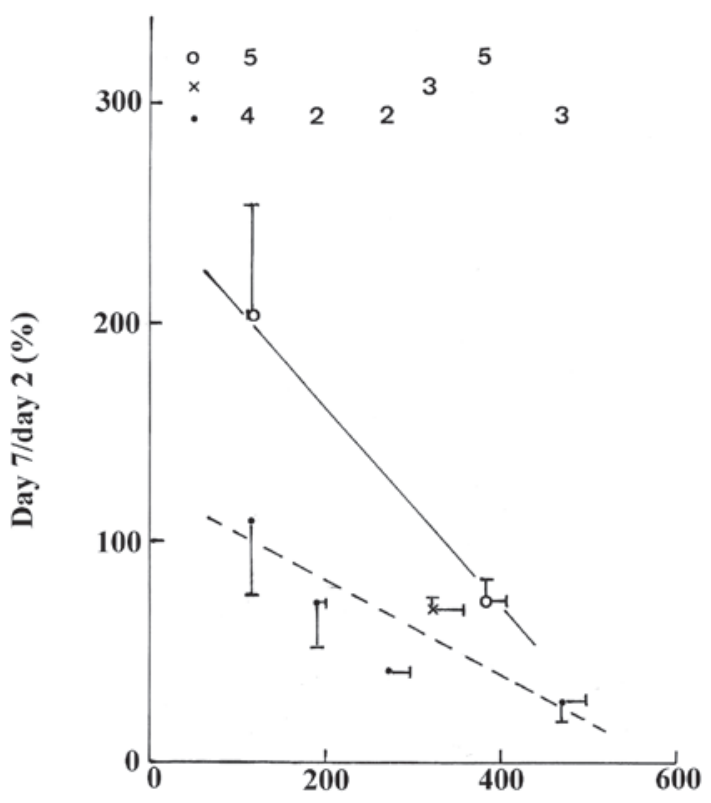

Day $2 /$ day $0(\%)$

Figure 2. Correlation between Day 7/Day 2 ratio in glycemia and the Day 2/Day 0 ratio in glycemia subsequent to streptozotocin (STZ) administration either to the control (open circles and solid line) or the experimental rats, injected either once $24 \mathrm{~h}$ prior to STZ administration (cross) or daily for 30 days prior to such an injection (closed circles and dashed line). Mean values $( \pm$ SEM) refer to the number of animals indicated at the top of the figure. The oblique solid and dashed lines are the regression lines.

the same incubation period. During the two successive incubations with STZ, insulin output averaged during the first and second incubation period $73.1 \pm 14.1 \%(\mathrm{n}=19 ; \mathrm{P}>0.16)$ and $14.4 \pm 2.0 \%(n=19 ; \mathrm{P}<0.006)$, respectively, of the mean reference values recorded in the sole presence of D-glucose, i.e., $100.0 \pm 11.9 \%(n=17)$ and $100.0 \pm 5.9 \%(n=20)$. In the presence of STZ and the $\mathrm{H}_{2} \mathrm{O}$-methanol extract, the average insulin output during the first and second incubation periods was $94.2 \pm 11.5 \%(n=18)$ and $42.6 \pm 7.1 \%(n=19)$, respectively. Consequently, this output was higher compared to the islets exposed to STZ without the $\mathrm{H}_{2} \mathrm{O}$-methanol extract, and the difference was highly significant $(\mathrm{P}<0.001)$ during the second incubation. These findings are shown in the left panel of Fig. 1, where all results are expressed relative to the mean value found within the same experiment(s) during the first incubation period in islets exposed to $16.7 \mathrm{mM}$ D-glucose. Notably, as shown in the right panel of Fig. 1, during the second incubation the $\mathrm{H}_{2} \mathrm{O}$-methanol extract increased to almost three times the D-glucose-induced insulin output in islets exposed to STZ $(294.9 \pm 51.2 \%$; $\mathrm{df}=37)$, distinct $(\mathrm{P}<0.005$ or less $)$ from only $112.4 \pm 12.8 \%(\mathrm{df}=74)$ in islets not exposed to STZ and $128.9 \pm 24.4 \%$ ( $\mathrm{df}=35$ ) during the first incubation of islets exposed to STZ. The $\mathrm{H}_{2} \mathrm{O}$-methanol extract presence/absence ratio in the insulin output was expressed as percentages.

In vivo experiments. The average basal glycemia after overnight starvation in the control rats and those injected with the aqueous extract (90 $\mathrm{mg} / \mathrm{kg}$ body wt. intraperitoneally) daily for 21 days was $6.28 \pm 0.22 \mathrm{mM}(\mathrm{n}=10)$ and $6.22 \pm 0.21 \mathrm{mM}(\mathrm{n}=11)$, respectively, prior to the injection of STZ. Two days after 
the injection of STZ $(0.25 \mathrm{mmol} / \mathrm{kg}$ body wt.), the glycemia (after overnight starvation) was increased to $260.4 \pm 28.2 \%$ $(\mathrm{n}=24, \mathrm{P}<0.001)$. The Day 2/Day 0 ratio was relatively variable (range, 106.1-523.7\%). A negative correlation $(\mathrm{P}<0.06$ or less) was observed between the Day 2/Day 0 ratio and the Day 7/Day 2 glycemia ratio in the control rats injected with saline $(5.0 \mathrm{ml} / \mathrm{kg}$ body wt.) daily for 21 days and the experimental rats injected with the aqueous extract daily (Fig. 2). For instance, the Day 7/Day 2 ratio decreased in the control rats $(\mathrm{P}<0.04)$ from $203.5 \pm 50.8 \%(\mathrm{n}=5)$ to $74.1 \pm 9.4 \%(\mathrm{n}=5)$ when the Day 2/Day 0 ratio increased $(\mathrm{P}<0.001)$ from $116.3 \pm 2.9 \%$ $(n=5)$ to $382.8 \pm 23.6 \%(n=5)$.

The covariance analysis demonstrated, however, that the slope of the regression line between the Day 7/Day 2 ratio and the corresponding Day 2/Day 0 ratio was $50 \%$ lower $(\mathrm{P}<0.06)$ in the experimental $(-0.2101)$ compared to the control rats (-0.4531). Moreover, regarding the control and experimental rats with a comparably low $(116.3 \pm 2.9$ and $115.4 \pm 2.5 \%$, respectively; $\mathrm{n}=4-5$ ) or comparably high Day 2/Day 0 ratio (382.8 \pm 23.6 and $389.9 \pm 51.1 \%$, respectively; $n=5$ in both cases), the Day 7/Day 2 ratio found in the experimental rats represented no more $(\mathrm{P}<0.009)$ than $49.5 \pm 8.5 \%(\mathrm{n}=9)$ of the mean corresponding values present in the control animals $(100.0 \pm 13.2 \% ; n=10)$. The absolute glycemia values recorded on Day 7 were also $50 \%$ lower $(\mathrm{P}<0.004)$ in the experimental rats $(8.07 \pm 1.19 \mathrm{mM}, \mathrm{n}=11)$ compared to the control animals (16.38 $\pm 2.16 \mathrm{mM}, \mathrm{n}=10)$.

As is evident in Fig. 2, there was little to distinguish in terms of the Day 7/Day 2 ratio between the 3 rats injected once with the aqueous extract $24 \mathrm{~h}$ prior to STZ administration and the 5 control animals exhibiting a comparable Day 2/Day 0 ratio. However, the mean glycemia at Day 7 tended to be lower $(\mathrm{P}<0.07)$ in the former 3 rats $(11.67 \pm 0.95 \mathrm{mM})$ compared to the latter 5 animals $(19.18 \pm 2.39 \mathrm{mM})$.

\section{Discussion}

The present results provide two independent sets of findings demonstrating the protective action of Citrullus colocynthis extracts against the deleterious effects of STZ on both glucose-stimulated insulin secretion from rat-isolated pancreatic islets and glucose homeostasis in rats injected with the $\beta$-cytotoxic agent.

In the in vitro experiments, the STZ-induced impairment of glucose-stimulated insulin release was, as expected from prior studies $(7,8)$, markedly more pronounced during the second rather than the first 60-min incubation. Similarly, the protective action of the $\mathrm{H}_{2} \mathrm{O}$-methanol extract from Citrullus colocynthis against the STZ-induced alteration of insulin output was, in relative terms, most pronounced during the second incubation period (Fig. 1). Notably, under the present experimental conditions and in the absence of STZ, the $\mathrm{H}_{2} \mathrm{O}$-methanol extract failed to induce a statistically significant increase in insulin release at the high concentration of D-glucose $(16.7 \mathrm{mM})$ used in the present experiments.

In the in vivo experiments, the crude aqueous extract of Citrullus colocynthis seeds was injected intraperitoneally for 21 days prior to STZ administration. Results showed that it minimized the severity of hyperglycemia found subsequent to overnight starvation 7 days after STZ administration (Fig. 2).
Thus, findings of the in vivo experiments showed the average glycemia 7 days after the STZ injection to be $11.67 \pm 0.95 \mathrm{mM}$ $(\mathrm{n}=3)$ and $8.07 \pm 1.19 \mathrm{mM}(\mathrm{n}=11)$, respectively, in rats injected intraperitoneally with the aqueous extract only once $24 \mathrm{~h}$ prior to STZ administration and daily for 21 days prior to STZ administration, compared to $16.38 \pm 2.16 \mathrm{mM}(\mathrm{n}=10)$ in the control rats injected daily with saline for 21 days prior to STZ administration. After 21 daily injections, the difference between the control and experimental rats remained statistically significant, even when allowance was made for the relative severity of hyperglycemia 2 days after STZ administration.

In conclusion, the present study has demonstrated that, in addition to the known beneficial effects of Citrullus colocynthis extracts on glucose homeostasis, when injected in either alloxan- or STZ-diabetic rats, this extract also suppressed the immediate and direct effect of STZ on insulin-producing cells and, by doing so, minimized the perturbation of glucose homeostasis otherwise induced by this $\beta$-cytotoxic agent.

\section{Acknowledgements}

The authors would like to thank C. Demesmaeker for her secretarial support.

\section{References}

1. Zaree AB, Fallahhossini F, Sharifabady R, Norooz zadeh A, Emani $\mathrm{H}$ and Ghoshooni $\mathrm{H}$ : The effect of Citrullus colocynthis extract on preventing/reducing streptozotocin-induced diabetes in rat. Kowsar Med J 12: 13-20, 2007.

2. Dallak M, Al-Khateeb M, Al-Hashem F, Bashir N, Abbas M, Elessa $\mathrm{R}$ and Khalil $\mathrm{M}$ : In vivo, acute, normo-hypoglycemic, ant-hyperglycemic, insulinotropic actions of orally administered ethanol extract of Citrullus colocynthis (L.) schrab pulp. Am J Biochem Biotechnol 5: 118-125, 2009.

3. Benariba N, Djaziri R, Zerriouth BH, Boucherit K, Louchami K, Sener A and Malaisse WJ: Antihyperglycemic effect of Citrullus colocynthis seed aqueous extracts in streptozotocin-induced diabetic rats. Met Funct Res Diab 2: 71-76, 2009.

4. Malaisse-Lagae F and Malaisse WJ: Insulin release by pancreatic islets. In: Methods in Diabetes Research. Larner J and Pohl S (eds). Vol. I, part B. John Wiley and Sons, New York, pp147-152, 1984.

5. Malaisse WJ, Maggetto C, Leclercq-Meyer V and Sener A: Interference of glycogenolysis with glycolysis in pancreatic islets from glucose-infused rats. J Clin Invest 91: 432-436, 1993.

6. Leclercq-Meyer V, Marchand J, Woussen-Colle MC, Giroix M-H and Malaisse WJ: Multiple effects of leucine on glucagon, insulin and somatostatin secretion from the perfused rat pancreas. Endocrinology 116: 1168-1174, 1985.

7. Golden P, Baird L, Malaisse WJ, Malaisse-Lagae F and Walker M: Effect of streptozotocin on glucose-induced insulin secretion by isolated islets of Langerhans. Diabetes 20: 513-518, 1971.

8. Golden P, Baird L, Malaisse WJ, Malaisse-Lagae F and Walker MM: Effect of 1-methyl-1-nitrosourea and streptozotocin on glucose-induced insulin secretion by isolated islets of Langerhans. Diabetologia 12: 207-209, 1976. 